\title{
Ignition Temperature and Surface Emissivity of Heterogeneous Loosely Packed Materials from Pyrometric Measurements
}

\author{
BOGDAN Z. DLUGOGORSKI ${ }^{1,2}$, SAMORN HIRUNPRADITKOON ${ }^{1}$, ERIC M. KENNEDY ${ }^{1}$ \\ ${ }^{1}$ School of Engineering, The University of Newcastle, NSW 2308, Australia \\ ${ }^{1,2}$ School of Engineering and Information Technology, Murdoch University, WA 6150, Australia \\ B.Dlugogorski@murdoch.edu.au
}

\begin{abstract}
This paper reports the ignition temperature and emissivity of heterogeneous materials characterised by high void fraction of between 0.92 and 0.94 and composed of loose particles of shredded grass and paper, planed wood, shredded plastic bags, as well as sugar and bread, with about $95 \%$ of the particles (by mass) of less than $50 \mathrm{~mm}$ in size. These materials reflect a typical composition and void fraction of so-called refusederived fuels (RDF), which are obtained from municipal solid waste, then densified and combusted for energy recovery. An infrared pyrometer, with a spectral response range of 8 to $14 \mu \mathrm{m}$, recorded the surface temperature of the surrogate RDF, prior to the onset of the flaming combustion, in a stand alone mass loss calorimeter operated at 20 and $45 \mathrm{~kW} \mathrm{~m}^{-2}$. The overlapping spectral ranges of the pyrometer and the radiator heater necessitated the development of a practical methodology to obtain the actual surface temperature from the apparent measurements, which included the effect of the reflected radiation. In addition to surface temperatures $\left(292-325{ }^{\circ} \mathrm{C}\right.$ for $20 \mathrm{~kW} \mathrm{~m}{ }^{-2}$ and $250-294{ }^{\circ} \mathrm{C}$ for $\left.45 \mathrm{~kW} \mathrm{~m}^{-2}\right)$, in this contribution, we estimate the actual emissivities $(0.95-0.98)$ of the materials from the intensity of the reflected radiation.
\end{abstract}

KEYWORDS: cone calorimeter, ignitability, piloted ignition, ignition temperature, ignition delay, ignition mechanism, heat transfer in fires, fire properties, emissivity, firepoint, biofuels

\section{NOMENCLATURE}

c constant that accounts for view factor, Greek surface area and pyrometer response

$E \quad$ energy reaching the pyrometer $(\mathrm{kW}$ $\mathrm{m}^{-2}$ )

$E_{\alpha} \quad$ energy emitted $\left(\mathrm{W} \mathrm{m}^{-2}\right)$

$\alpha$

$\varepsilon$

$E_{\gamma} \quad$ energy reflected $\left(\mathrm{W} \mathrm{m}^{-2}\right)$

$\varepsilon_{\text {guess }}$

$\dot{q}^{\prime \prime} \quad$ heat flux $\left(\mathrm{W} \mathrm{m}^{-2}\right)$

$T_{a} \quad$ extrapolated apparent temperature (K) $\quad \sigma$

$T_{0} \quad$ initial sample temperature (K)

\author{
Absorptivity \\ emissivity within spectral range 8-14 \\ $\mu \mathrm{m}$ \\ pyrometer emissivity selected by \\ operator \\ reflectivity \\ Stefan-Boltzmann constant $\left(\mathrm{W} \mathrm{m}^{-2} \mathrm{~K}^{-4}\right)$
}

\section{INTRODUCTION}

The intention of this study was to measure the ignition temperature of loose materials composed of shredded pieces of grass, paper and wood mixed with small amounts of bread and sugar. Note that, in the fire safety literature, the term ignition temperature is also denoted as a firepoint temperature by analogy with flammable liquids, e.g. [1]. The fraction of each of the components was selected to correspond to a typical combustion fraction of the municipal solid waste collected from households in the city of Newcastle in Australia [2]. In recent decades, RDF have been extensively used for energy recovery (after densification) with large amounts of such materials stored in dedicated silos in preparation for combustion. Although RDF constitute an obvious fire hazard, little is known about their ignition properties and about the fundamental physical and chemical phenomena that define their ignition mechanism under fire conditions. 
The usual approach to measure the ignition temperature of solid specimens, prior to ignition, is to glue or otherwise attach a fine gauge thermocouple to the material's surface; Atreya et al. [3], Kashiwagi et al. [4] and Tran and White [5] provide examples of relevant experimental methodologies. However, this approach fails for loose heterogenous materials, for which the location of the surface cannot be defined precisely. In these situations, one must rely on non-intrusive pyrometric technique, bearing in mind that the reflection of the imposed irradiance complicates the measurements of the surface temperature.

One approach, to circumvent the last difficulty, has been to employ a radiation device and a pyrometer operating over disjoint spectral ranges. In practice, this can be accomplished by exposing specimens to radiation devices such as quartz lamps [6] or radiation arcs that function at wavelengths below 2.5-3.5 $\mu \mathrm{m}$, and to deploy pyrometers sensitive to infrared radiation at longer wavelengths. Introducing this methodology to a practical application, one needs to appreciate that absorptivity of lignocellulosic materials, and hence their emissivity as a consequence of the Kirchhoff law, displays a strong spectral dependence, decreasing to less than 0.4 at wavelengths below $3.5 \mu \mathrm{m}$ [6]. This results in slower heating rates of specimens exposed to quartz lamps and radiation arcs, in comparison to blackbody-like spectral radiation devices (e.g. the frustum radiator incorporated in cone calorimeters). The problem becomes especially acute prior to ignition, when the material at the surface has not yet undergone charring. An alternative approach, adopted in the present study, represents the use of a blackbody-like spectral radiation device in conjunction with a pyrometer functioning within the spectral range of the device (e.g. [7,8]). In this case, the signal recorded by a pyrometer combines the radiation emitted by the sample itself and the radiation reflected off the surface, necessitating a correction procedure to eliminate the effect of the reflected radiation [9].

From a fundamental perspective, the measurement of the surface temperature at ignition has attracted significant attention. This is because the ignition temperature represents one of the fire properties that gauge the material's propensity to ignition and fire spread. Fire safety researchers have collected numerous laboratory measurements of ignition temperature for a variety of solid fuels, with Babrauskas [10] assembling these measurements into a comprehensive handbook. However, except for polymeric foams (e.g. $[1,11,12])$, the ignition of multiphase materials characterised by large void fraction, under fire conditions, has escaped detailed investigation. Polymeric foams are the only exception, because their widespread use and the substantial fire hazards posed (these materials have been implicated in several fires with multiple fatalities) have attracted the attention of fire safety researchers. In contrast, the ignition of $\mathrm{RDF}$ and loose biofuels has been studied mainly under conditions relevant to energy recovery from RDF and biomass (e.g. [13-15]). Very few investigations concentrated on the ignition of shredded lignocellulosic and plastic materials, or their mixtures, under irradiance fluxes encountered in fires (e.g. [16]); that is below $100 \mathrm{~kW} \mathrm{~m}^{-2}$. The present paper intends to redress this situation.

\section{EXPERIMENTAL}

\section{Apparatus}

The application of a pyrometer to measure the surface temperature of a specimen directly in a cone calorimeter creates a considerable challenge. This is because the top surface of a specimen lies only $25 \mathrm{~mm}$ below the base of the cone heater. This geometric constraint precludes targeting a well-defined surface element for precise temperature measurement. Furthermore, the canopy inlet of the exhaust manifold encumbers access from above to the sample. To avoid these drawbacks, we set up a stand alone test section of the cone calorimeter, called a mass loss cone calorimeter, as shown in Fig. 1.

The mass loss cone calorimeter consisted of a cone temperature controller (Eurotherm 847) with four main control switches (power supply, temperature controller, igniter and load cell), a truncated cone (frustum shaped) electrical heater with a modified shutter gate, a sample holder, and a spark igniter. The surface of the specimen was located $25 \mathrm{~mm}$ below the lower surface of the cone heater base, as adopted in a standard cone calorimeter. All experiments reported in this article involved a piloted spark ignition. Ignition occurred within a few seconds after exposing the sample to the incident radiation. This necessitated modification of the shutter gate, which had to be moved quickly after the onset of each experiment. The modified gate consisted of a round shield plate operated by a handle. Further modifications of the mass 
loss included the addition of the side exhaust duct, shroud air in front of the pyrometer, and a computer based data acquisition system for recording the pyrometer signal. The thermocouples illustrated in Fig. 1 measured the evolution of the temperature profiles within the samples [17], with these measurements presented in ref. [18].

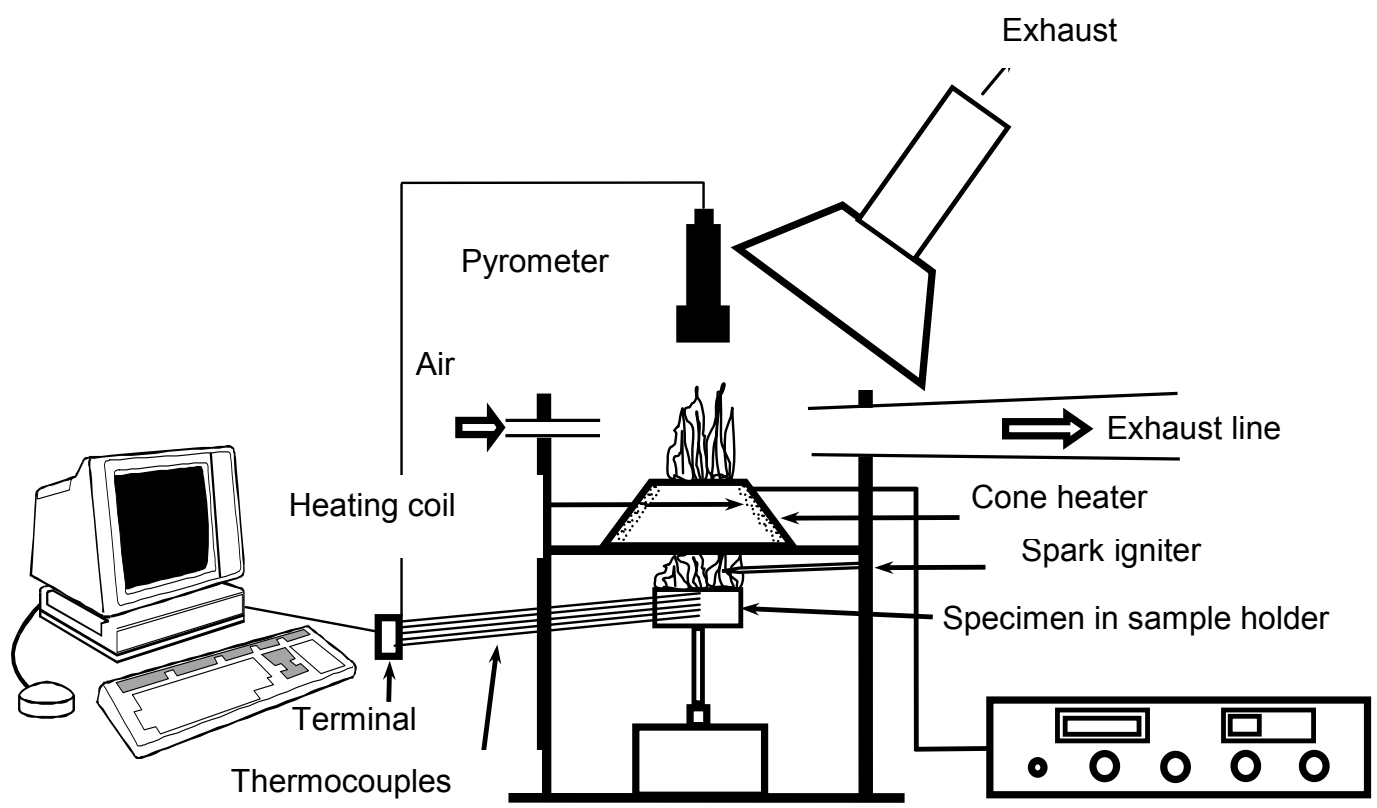

Cone calorimeter controller

Fig. 1. Schematic diagram (not to scale) of the instrument used to study the ignition of loosely packed particles of solid fuels.

A kaowool insulator covered the top surface of the shutter gate to reduce the reflection of the thermal radiation toward the pyrometer and to minimise the heating of the shutter gate itself. During preliminary experiments, we recognised that a hot shutter gate re-radiated the energy toward the sample material increasing its temperature prior to an experiment. The simultaneous opening of the shutter gate and removal of the kaowool rapidly exposed the sample to the desired irradiance, avoiding unwanted preheating of the material.

\section{Pyrometer}

A Raytek Thermalert (LTCF2 model) pyrometer, with spectral response of 8-14 $\mu \mathrm{m}$, was operated without a protective window. The spectral response of the instrument makes it appropriate for measuring the temperature between -18 and $500{ }^{\circ} \mathrm{C}$. The pyrometer displays an accuracy of $\pm 1 \%$ of the reading or \pm 1.4 ${ }^{\circ} \mathrm{C}$, whichever is greater. It exhibits the repeatability of $\pm 0.5 \%$ of reading or $\pm 0.7{ }^{\circ} \mathrm{C}$, whichever is greater. Its response time corresponds to $165 \mathrm{~ms}$, and it can resolve temperatures to $0.1{ }^{\circ} \mathrm{C}$. The minimum target size of $6.4 \mathrm{~mm}$ in diameter occurs for the instrument positioned at a distance of $200 \mathrm{~mm}$. The pyrometer requires the use of a sighting tool for precise targeting. An operator needs to select an estimate of the target emissivity, and for the experiments reported in this paper we selected 0.95 . We will demonstrate later how to deduce the actual emissivity, in the spectral range of 8 to $14 \mu \mathrm{m}$, from the experimental measurements.

During pre-ignition heating, the components of the surrogate RDF instantaneously warp, shrink, twist and deform as soon as the incident radiation targets the surface. In the course of the experimental program, this necessitated an increase in the surface area probed by the pyrometer, by adjusting the pyrometer vertically along the centre line of the cone frustum, for the pyrometer to be finally placed $30 \mathrm{~cm}$ above the specimen (Fig. 1). In this position, the pyrometer recorded the surface temperature readings from a target spot of 15 $\mathrm{mm}$ in diameter. 
Real time sampling of signals from the pyrometer's analogue output was conducted at $5 \mathrm{~ms}$ intervals with the data being stored on a PC running Labview 5.0 software and using a National Instruments data logger (PCI-6024E model with 24-bit resolution on 16 single-ended analogue inputs). The logger recorded the results for $40 \mathrm{~s}$, though the onset of flaming combustion forced the removal of the pyrometer well before this time limit. We selected the sampling time shorter than the response time of the pyrometer, to collect the response curve of the instrument just after the imposition of the irradiance. This allowed the extrapolation of the apparent surface temperature, to the irradiance. This in turn allowed the extrapolation of the apparent surface temperature, to the time instant immediately after opening of the shutter, to eliminate the response time of the instrument (Fig. 2). The instantaneous temperature rise between the initial temperature of the sample $\left(T_{0}\right)$ and the extrapolated apparent temperature $\left(T_{a}\right)$ at the time of opening the shutter is a consequence of the pyrometer detecting the radiation reflected from the sample. This occurred because the pyrometer operated in the range $(8-14 \mu \mathrm{m})$, within the spectral frequency of the radiation emitted by the heating spiral of the cone calorimeter and reflected by the sample. The section, entitled Emissivity and Temperature Correction, outlines the methodology to exploit this temperature jump to derive the actual value of the material emissivity.

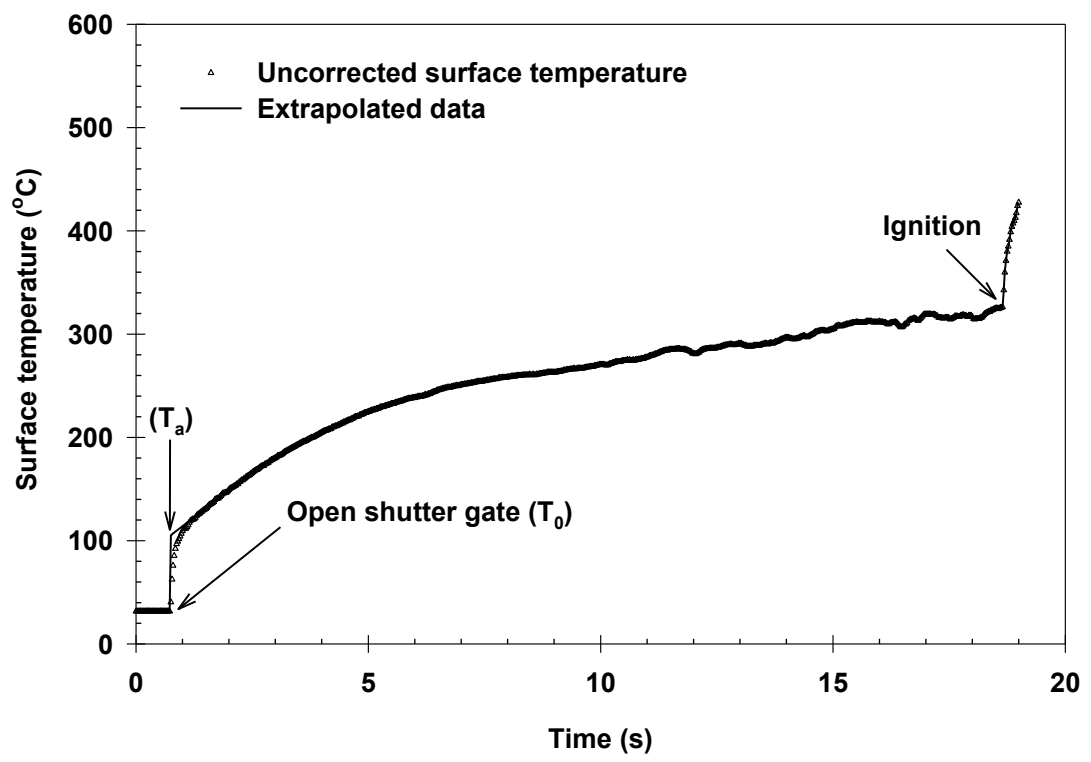

Fig. 2. Extrapolated temperature point to calculate the surface emissivity of RDF samples exposed to $20 \mathrm{~kW}$ $\mathrm{m}^{-2}$ irradiance; sample thickness and density are $40 \mathrm{~mm}$ and $50 \mathrm{~kg} \mathrm{~m}^{-3}$ respectively.

\section{Surrogate Material}

The experimental program included tests with the surrogate RDF, and separately with the individual components of the surrogate RDF. Table 1 presents the density of the component materials and their fractions in the surrogate RDF, with Fig. 3 showing a photograph of the material prior to an experiment. The samples dried in a convection oven and cooled down in a desiccator prior to experiments, with details presented in Hirunpraditkoon at al. [17]. The experiments involved one sample thickness $(40 \mathrm{~mm})$ and two densities, 37 and $50 \mathrm{~kg} \mathrm{~m}^{-3}$, depending on the material; $37 \mathrm{~kg} \mathrm{~m}^{-3}$ for planed wood and shredded paper, and $50 \mathrm{~kg} \mathrm{~m}^{-3}$ for RDF and shredded grass. These two densities correspond to void fractions of 0.94 and 0.92 , respectively (with the combined fraction of void space and intraparticle porosity of 0.97 and 0.96 ). The materials were prepared in such a way as to ensure that $95 \%$ of the particles (by weight) pass through 50 mm square screening, as stipulated by ASTM E828 (2001) for the so-called RDF-3 fuel.

Placing the RDF specimens on a kaowool mat minimised the heat-loss effects from the bottom of the sample. At each heat flux level, the experimental program included a minimum of five tests to examine the reproducibility of the experimental results, and to provide an estimate of the scatter in the data. Table 2 summarises the laboratory conditions for measuring the surface temperature of RDF and its components. 
Hirunpraditkoon et al. [17] discusses additional details of the experimental procedure and the thermophysical properties of the materials studied here.

Table 1. Density analysis of each component of the surrogate RDF used in this study [17].

\begin{tabular}{|c|c|c|c|c|}
\hline Sample & $\begin{array}{c}\text { Physical } \\
\text { composition } \\
\text { (wt \%) }\end{array}$ & $\begin{array}{c}\text { Solid } \\
\text { density } \\
\left(\mathrm{kg} \mathrm{m}^{-3}\right)\end{array}$ & $\begin{array}{l}\text { Particle } \\
\text { density } \\
\left(\mathrm{kg} \mathrm{m}^{-3}\right)\end{array}$ & $\begin{array}{c}\text { Internal } \\
\text { porosity } \\
\%\end{array}$ \\
\hline Newspaper & 12.75 & 1410 & 857 & 39.2 \\
\hline White paper & 12.75 & 1480 & 768 & 48.1 \\
\hline Planed Radiata Pine & 6.1 & 1310 & 390 & 70.2 \\
\hline Dried grass & 58.5 & 1160 & 580 & 50 \\
\hline Plastic bag & 4.9 & 890 & 890 & 0 \\
\hline Bread & 2.5 & 653 & 196 & 70 \\
\hline Sugar & 2.5 & 1581 & 1580 & 0 \\
\hline $\mathrm{RDF}$ & & 1210 & 600 & 50.8 \\
\hline
\end{tabular}

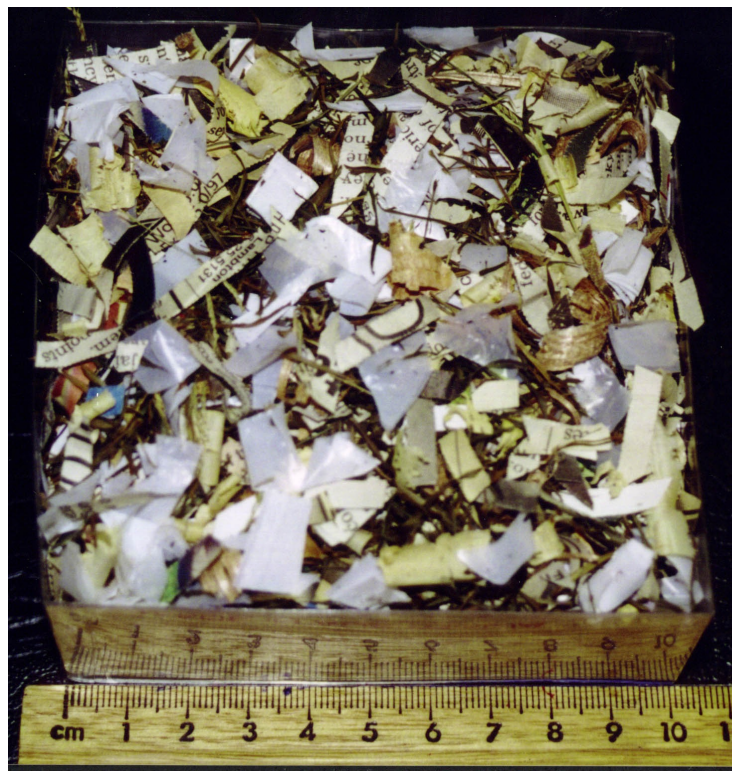

Fig. 3. Photograph of oven-dried surrogate RDF material used in the present investigation [17].

\section{EMISSIVITY AND TEMPERATURE CORRECTION}

This section presents a correction methodology to derive the actual temperature histories prior to ignition from apparent measurements, and provides examples of the corrected surface temperature histories for specimens of the surrogate RDF material and its components. As soon as the shutter gate opens, the pyrometer records both the energy emitted by the sample and the energy reflected off the material's surface. This can be written as,

$$
E=E_{\alpha}+E_{\gamma}
$$

where $E$ denotes the total energy reaching the pyrometer, $E_{\alpha}$ the energy emitted by the material, which at $t=0$ remains at the ambient temperature $\left(T_{0}\right.$, in $\left.\mathrm{K}\right)$, and $E_{\gamma}$ signifies the reflected energy. 
Table 2. Test conditions for studying heat transfer prior to ignition.

\section{Test conditions}

- $\quad$ specimen holder size

- specimen orientation

- $\quad$ ignition source

- heat shutter assembly

- ventilation

- inlet gas flow

- $\quad$ surface temperature

- $\quad$ sample thickness

- irradiance
$100 \times 100 \mathrm{~mm}$, maximum thickness $50 \mathrm{~mm}$ horizontal (face up) spark ignition interlocks with hand operated lever

a round shutter plate operated with a handle

no

ambient

pyrometer

$40 \mathrm{~mm}$

20 and $45 \mathrm{~kW} \mathrm{~m}^{-2}$

\section{Sample density $\left(\mathrm{kg} \mathrm{m}^{-3}\right)$}

- planed Radiata Pine

- newspaper and white paper (50\% each)

- grass

- $\mathrm{RDF}$

The internal electronics of the pyrometer convert $E$ into the apparent surface temperature $\left(T_{a}\right.$, in $\left.\mathrm{K}\right)$ from the following expression,

$$
E=c \varepsilon_{\text {guess }} \sigma T_{a}^{4}
$$

where $c$ corresponds to a constant that accounts for the view factor as well as the surface area and response of the pyrometer's sensor, $\varepsilon_{\text {guess }}$ represent the pyrometer's emissivity selected by the operator, which in the present experiments denotes a guessed value of 0.95 .

The following equation expresses the energy emitted by the sample just after the shutter gate opens and no heating has yet occurred

$$
E_{\alpha}=c \varepsilon \sigma T_{0}^{4}
$$

where $\varepsilon$ represents the actual emissivity in the spectral range of 8 to $14 \mu \mathrm{m}$.

If one makes the usual assumption that the Kirchhoff law applies, that is, the emissivity and absorptivity coefficients are equal $(\varepsilon=\alpha)$, then

$$
\alpha+\gamma=1 \text { or } \gamma=1-\varepsilon
$$

where $\gamma$ denotes the reflectivity coefficient. Equation 4 assumes an opaque material, which implies partial absorption and partial reflection of the incident radiation at the material's surface (no in-depth absorption).

Thus, the energy reflected off the specimen that reaches the pyrometer sensor corresponds to

$$
E_{\gamma}=c(1-\varepsilon) \dot{q}^{\prime \prime}
$$

where $\dot{q}^{\prime \prime}$ stands for the irradiance. Substituting Equations 2, 3 and 5 into Equation 1 leads to the expression for the actual emissivity of the material, 


$$
\varepsilon=\frac{\dot{q}^{\prime \prime}-\varepsilon_{\text {guess }} \sigma T_{a}^{4}}{\dot{q}^{\prime \prime}-\sigma T_{0}^{4}}
$$

Note that, the constant $c$ incorporates the effect of a view factor, and that the specimen surface is assumed to be diffuse; i.e., the surface has properties independent of direction. This means that, the same view factor applies to energy emitted by (Eq. 3) and reflected off (Eq. 5) the specimen surface. As a digression, the view factor between the cone frustum heater and the specimen surface, at the specimen centre point, is in the order of $0.75( \pm 0.7 \%)$ [19]. However, the present analysis deals only with the exchange of thermal radiation between the sample and the pyrometer. Figure 4 summarises all values of emissivity obtained from replicated experiments with planed wood, paper, grass and the surrogate RDF. All materials studied exhibit similar emissivities, with the values varying from 0.95 to 0.98 , for the spectral range of the instrument. This shows a minor correction to the initial estimate of emissivity of 0.95 . Note that, the large uncertainty of ignition temperature (vide infra), as a consequence of the non-uniformity of the fuel, overrides the error in surface emissivity. For the same reason, the present analysis neglects the effect of indepth absorption of the thermal radiation. Such analyses have been performed recently by several research groups for solid polymeric fuels such as PMMA [20-22]. Once the actual emissivity of the material has been calculated, one can correct the entire temperature curve. The expression for the correction ensues by replacing Equations 2, 3 and 5 into Equation 1 to obtain $T_{0 \text {; }}$ the subscript is dropped to indicate the dependence of the temperature on time, as inscribed explicitly in Equation 7,

$$
T(t)=\left(\frac{\varepsilon_{\text {guess }} \sigma T(t)_{a}^{4}-(1-\varepsilon) \dot{q}^{\prime \prime}}{\varepsilon \sigma}\right)^{1 / 4} .
$$

Equation 7, which applies to each point after the opening of the shutter gate, assumes a constant irradiance, a reasonable postulate, as only a very small amount of the incoming radiation would be absorbed in the gas phase by the evolving products of the thermal decomposition. Figure 5 illustrates the typical corrected and uncorrected temperature histories of the surrogate RDF exposed to the irradiance of $20 \mathrm{~kW} \mathrm{~m}^{-2}$. (Although Fig. 5 plots the temperature histories in celsius, Equation 7 gives the temperature in units of kelvins.) For this experiment, ignition occurs $18 \mathrm{~s}$ after the opening of the shutter gate, and at this point the surface temperature reaches $320{ }^{\circ} \mathrm{C}$.

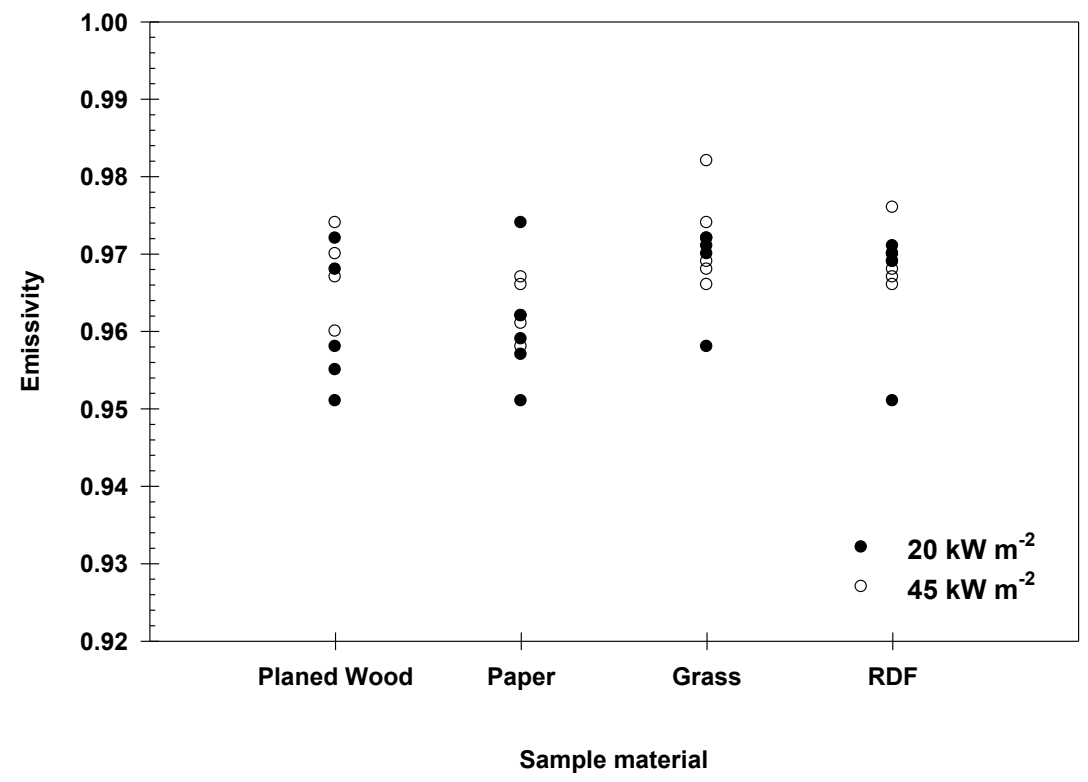

Fig. 4. Replicates of the emissivity of oven dried RDF and its components, at the irradiance levels of 20 and $45 \mathrm{~kW} \mathrm{~m}^{-2}$. 
At room temperature, $14 \%$ of the energy emitted by a grey radiator lies below $8 \mu \mathrm{m}$ and $49 \%$ above 14 $\mu \mathrm{m}$. At $300{ }^{\circ} \mathrm{C}$, the corresponding numbers stand for 56 and $15 \%$. This means that, a pyrometer operating between 8 and $14 \mu \mathrm{m}$, at any one time prior to ignition, registers at least $29 \%$ of the energy leaving the sample. At room temperature, the energy not registered by the pyrometer is carried mainly at wavelengths above $14 \mu \mathrm{m}$. After ignition, energy not registered by the pyrometer is conveyed at wavelengths below 8 $\mu \mathrm{m}$. This provides natural averaging of the emissivity coefficient as a function of temperature and wavelength. The wavelength ranges associated with the water vapour absorption (5.6-8 $\mu \mathrm{m})$ and the low values of the emissivity coefficient $(<3.5 \mu \mathrm{m})$ remain outside the pyrometer's sensitivity bands. Thus a pyrometer functioning between 8 and $14 \mu \mathrm{m}$ implies the most suitable choice for the present measurements. For the same reasons, Urbas and Parker [8] selected an infrared pyrometer with the sensitivity band of 8-12 $\mu \mathrm{m}$ for their study on the ignition of wood.

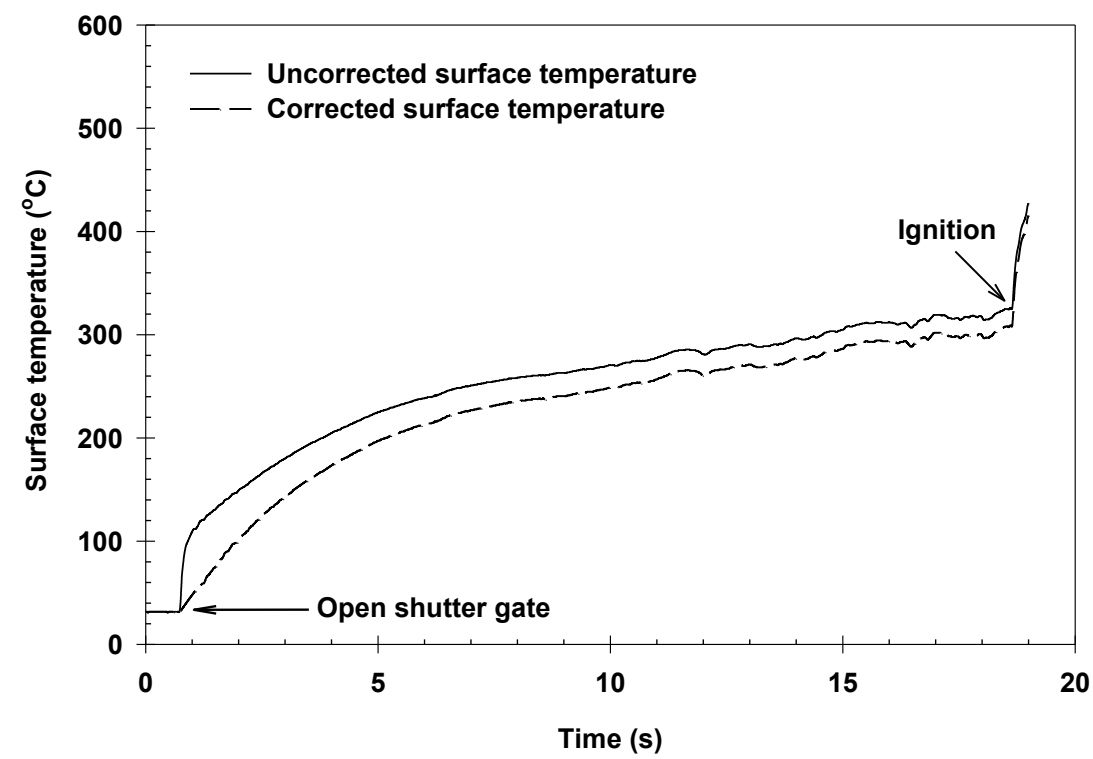

Fig. 5. Uncorrected and corrected surface temperature histories for RDF samples exposed to $20 \mathrm{~kW} \mathrm{~m}^{-2}$ irradiance; sample thickness and density are $40 \mathrm{~mm}$ and $50 \mathrm{~kg} \mathrm{~m}^{-3}$ respectively.

We conclude this manuscript by remarking that, the emissivity coefficient influences the surface temperature of the material during heating. For the type of materials considered in this investigation, this influence remains negligible, because the emissivity coefficient is near unity. Lower values of the emissivity give rise to higher reflectivity coefficients; which corresponds to a slower rate of heating of the sample. Setting $\varepsilon$ equal to 1 represents the usual assumption in fire studies (e.g. [8] among others), which would be justifiable in the present case as well. From a physical standpoint, this assumption entails the absence of reflected radiation. However, we stress that, in this investigation the actual value of the material's emissivity was derived from the experimental measurements and then used to correct the measurements of the surface temperature; allowing one to factor out the effect of reflected radiation, in contrast with the previous studies.

\section{RESULTS AND DISCUSSION}

Table 3 provides ranges of the ignition times and surface temperatures at ignition for oven dried surrogate RDF and its components (planed wood, shredded paper and grass). Figures 6-9 also plot all results of the replicated surface measurements. For each material, the top panes in Figs. 6-9 present typical surface temperature histories deduced from the pyrometer readings, with the ignition identified by a sudden temperature rise. For the both heat fluxes used and for all samples examined, a range of surface ignition temperatures was measured, with the usual difference between the highest and the lowest values of about $50{ }^{\circ} \mathrm{C}$, or $15-20 \%$ of the average value. The results disclose a $10 \mathrm{~s}$ variation in the time to ignition at the irradiance of $20 \mathrm{~kW} \mathrm{~m}^{-2}$ and $2 \mathrm{~s}$ at $45 \mathrm{~kW} \mathrm{~m}^{-2}$. 
The current results appear to indicate that, the surface temperature at ignition tends to decrease with increasing irradiance; see Figs. 6b, 7b, $8 \mathrm{~b}$ and $9 \mathrm{~b}$. Other researchers who studied the ignition of pyrolysing solid fuels, such as wood, reported similar findings [25-26]. At low levels of the irradiant heat flux, lignocellulosic materials volatilise at slower rates. Since the ignition requires the accumulation of pyrolysates to exceed the lower flammability limit, lower heat fluxes require longer pyrolysis time, leading to higher temperature at ignition.

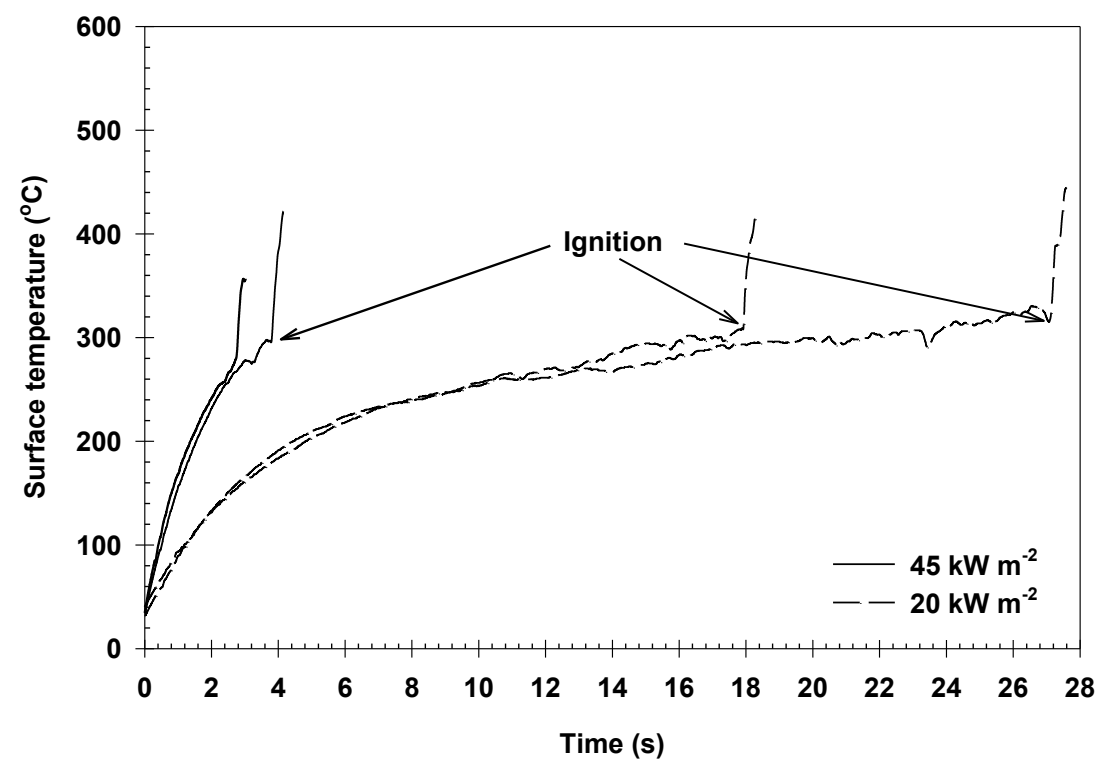

$\mathbf{a}$

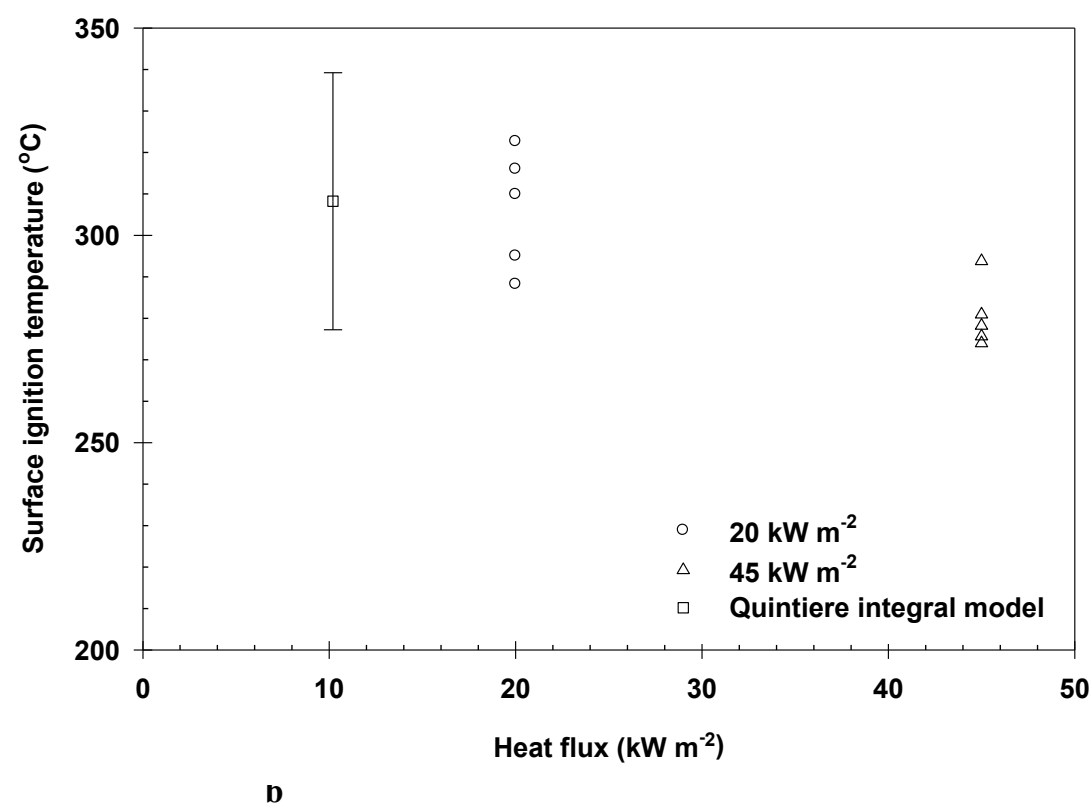

Fig. 6. Temperature measurements for dried RDF sample $40 \mathrm{~mm}$ in thickness and $50 \mathrm{~kg} \mathrm{~m}^{-3}$ in density at irradiance levels of 20 and $45 \mathrm{~kW} \mathrm{~m}^{-2}$; a) replicates of the surface temperature histories; b) summary of the ignition temperatures. 
Figure $6 \mathrm{~b}$ also compares the measured surface temperature at ignition with the critical (pyrolysis) temperature calculated by following Quintiere's integral approach [26,27]. The pyrolysis temperature is computed at the critical heat flux, which Hirunpraditkoon et al. [17] estimated as $10 \pm 2 \mathrm{~kW} \mathrm{~m}^{-2}$ from the experiments performed under the cone calorimeter. A comparison between the present measurements and the calculations from the integral model demonstrates a reasonable agreement, although, one should appreciate the very approximate nature of this agreement. Strictly speaking, Quintiere's approach assumes a constant net heat flux entering the material and the surface temperature at ignition to be independent of the imposed irradiance [28]. The present set of the experimental measurements does not satisfy either of the assumptions.

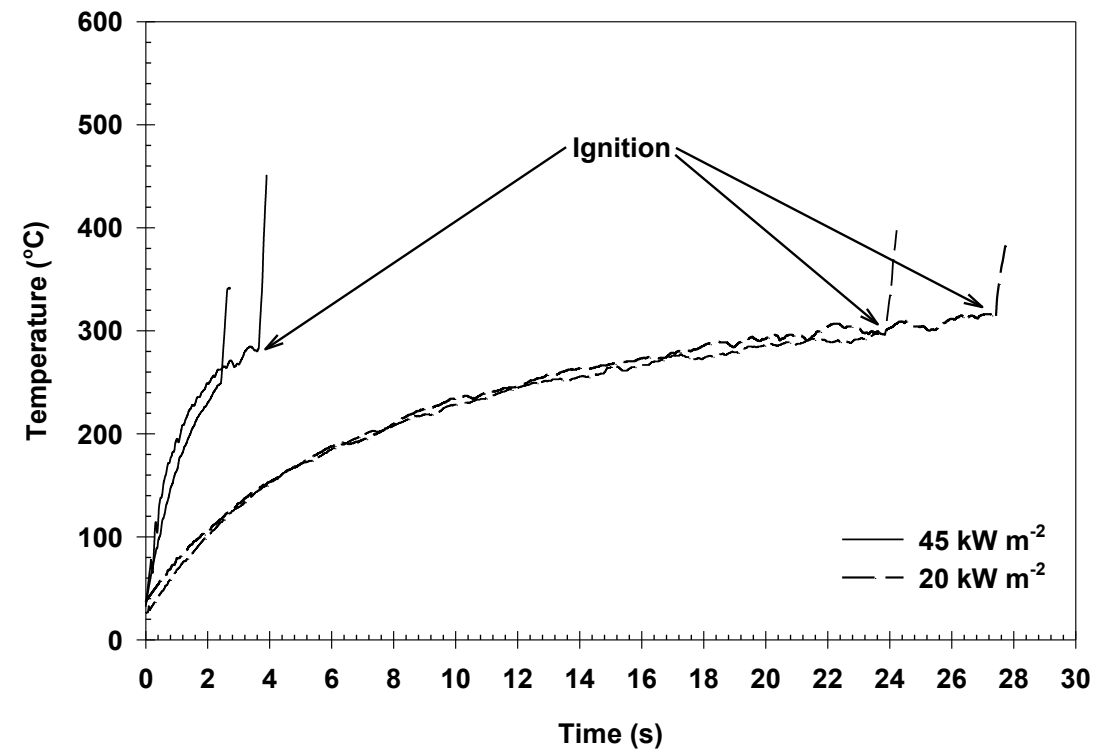

a

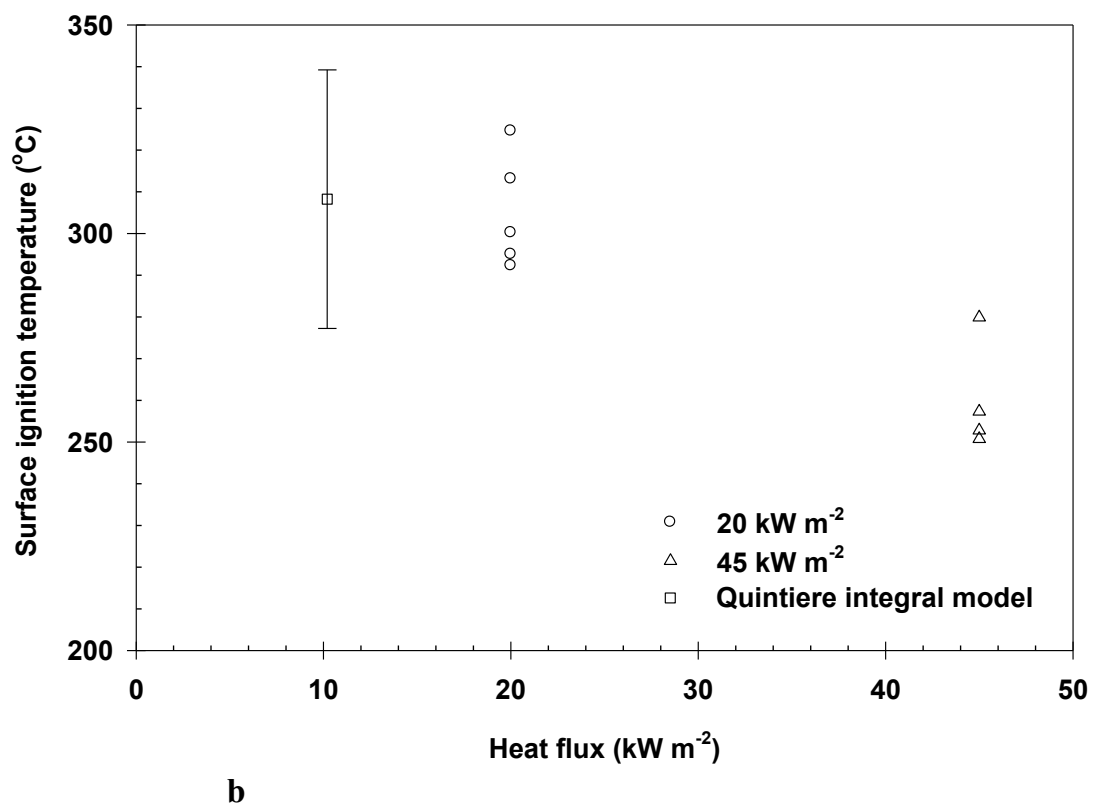

Fig. 7. Temperature measurements for oven dried planed wood sample $40 \mathrm{~mm}$ in thickness and $37 \mathrm{~kg} \mathrm{~m}^{-3}$ in density at irradiance levels of 20 and $45 \mathrm{~kW} \mathrm{~m}^{-2}$; a) replicates of the surface temperature histories; b) summary of the ignition temperatures. 
The mass loss calorimeter with an exhaust manifolds placed to the side and above the heating cone (Fig. 1) imposes air flow pattern around the samples that may be different than that induced by the air flowing through the extraction canopy of the cone calorimeter. This consideration may affect the convective heat transfer coefficient applied to calculate cooling of the specimen's surface prior to ignition. However, a comparison between the measurements of the ignition time presented in this paper in the mass loss cone (Table 3) with those included in Table 7 in Hirunpraditkoon et al. [17], for the ignition of dried RDF in the cone calorimeter, cannot discern this effect. The latter data for RDF-3 of density of $50 \mathrm{~kg} \mathrm{~m}^{-3}$ show the experimental scatter of 1.8 and $3.2 \mathrm{~s}$ as compared to 2.5-3.6 s of Table 3. As both ranges overlap, one concludes no variation in the convective heat transfer coefficient between the two geometries.

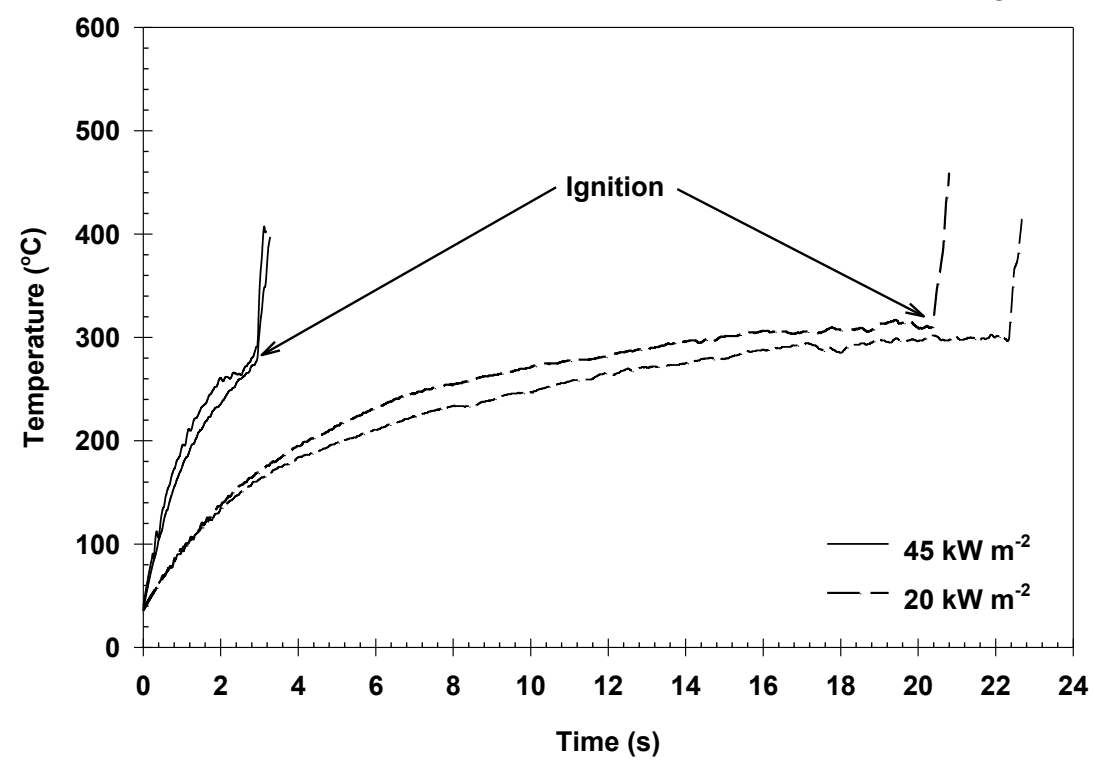

a

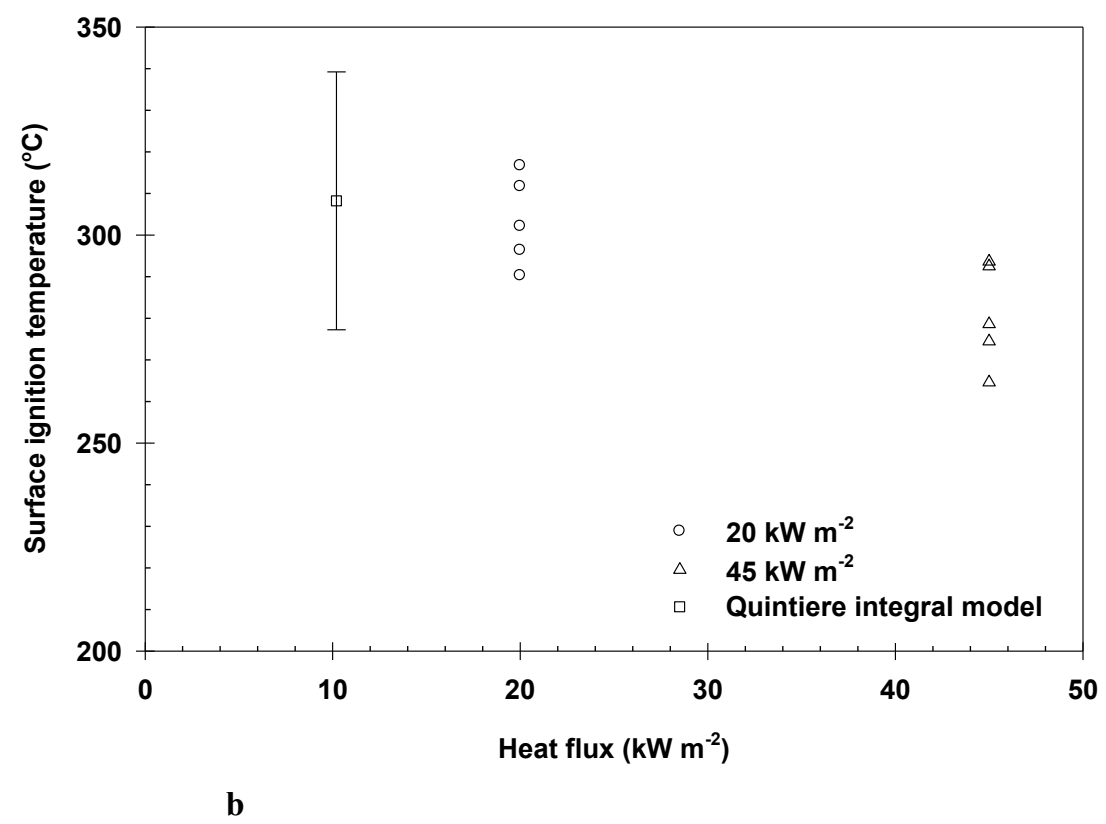

Fig. 8. Temperature measurements for oven dried paper sample $40 \mathrm{~mm}$ in thickness and $37 \mathrm{~kg} \mathrm{~m}^{-3}$ in density at irradiance levels of 20 and $45 \mathrm{~kW} \mathrm{~m}^{-2}$; a) replicates of the surface temperature histories; b) summary of the ignition temperatures. 


\section{CONCLUSIONS}

The values of the emissivity deduced from the measurements display no dependence on the imposed irradiance ( 20 and $45 \mathrm{~kW} \mathrm{~m}^{-2}$ ), varying between 0.95 and 0.98 as a result of the experimental scatter. The surface temperature at ignition seems to decrease with increasing heat flux, ranging between 288 and 323 ${ }^{\circ} \mathrm{C}$ at $20 \mathrm{~kW} \mathrm{~m}^{-2}$ (ignition delay 17.4-27.1 s), and between 274 and $294{ }^{\circ} \mathrm{C}$ at $45 \mathrm{~kW} \mathrm{~m}^{-2}$ (ignition delay 2.5$3.6 \mathrm{~s}$ ); from five replicate measurements at each irradiance. Similar dependence of the surface temperature at ignition on the imposed heat flux arises for the high-void-fraction materials composed of only one type of particles, such as planed wood of Radiata Pine, shredded paper or grass. These results indicate the capacity of loose materials containing lignocellulosic to ignite swiftly.

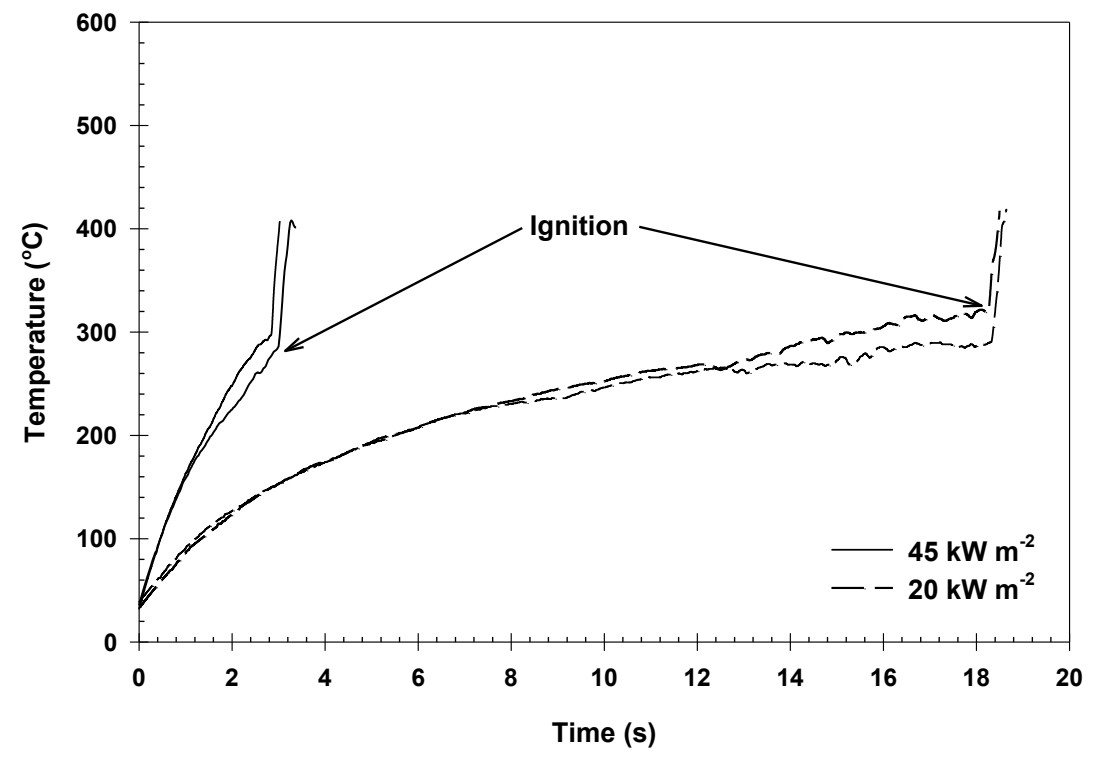

$\mathbf{a}$

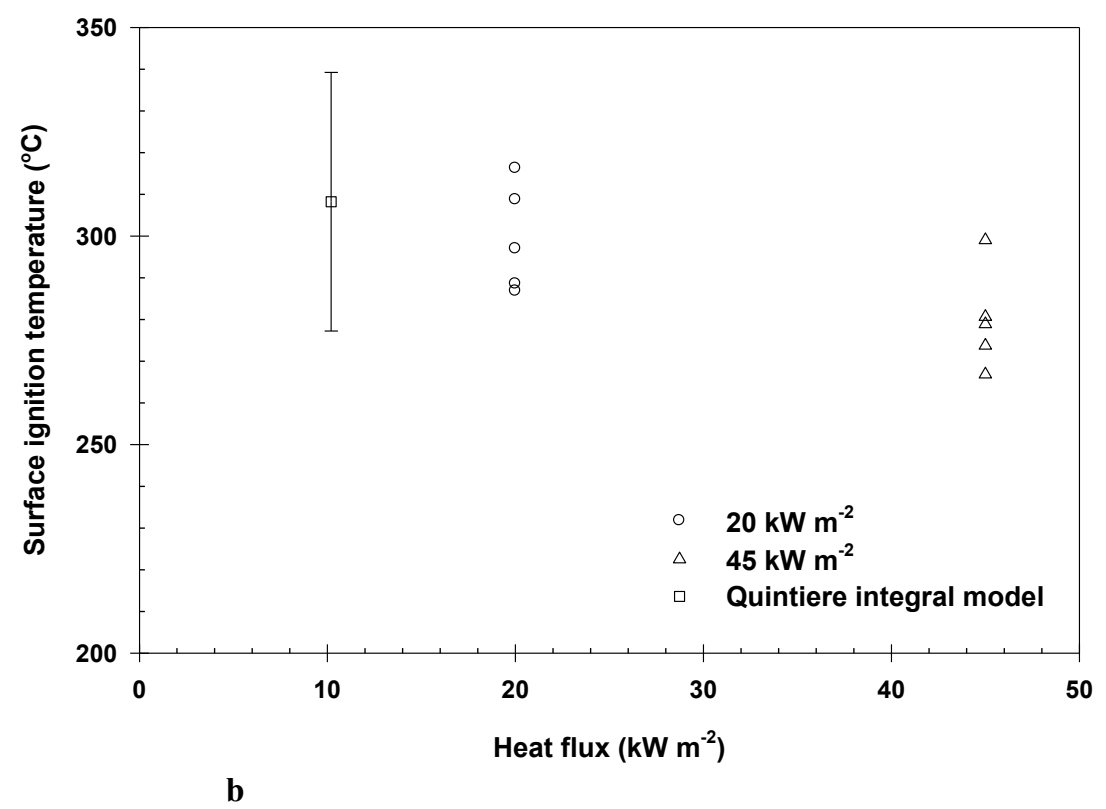

Fig. 9. Temperature measurements for oven dried grass sample $40 \mathrm{~mm}$ in thickness and $50 \mathrm{~kg} \mathrm{~m}^{-3}$ in density at irradiance levels of 20 and $45 \mathrm{~kW} \mathrm{~m}^{-2}$; a) replicates of the surface temperature histories; b) summary of the ignition temperatures. 
Table 3. Time to ignition and surface ignition temperatures for materials studied, at two different irradiances.

\begin{tabular}{|c|c|c|c|c|}
\hline \multirow{2}{*}{ Sample } & \multicolumn{2}{|c|}{ Ignition time (s) } & \multicolumn{2}{|c|}{ Surface ignition temperature $\left({ }^{\circ} \mathrm{C}\right)$} \\
\hline & $20 \mathrm{~kW} \mathrm{~m}^{-2}$ & $45 \mathrm{~kW} \mathrm{~m}^{-2}$ & $20 \mathrm{~kW} \mathrm{~m}^{-2}$ & $45 \mathrm{~kW} \mathrm{~m}^{-2}$ \\
\hline Planed Radiata Pine & $18.2-27.6$ & $2.3-4.5$ & $292-325$ & $250-280$ \\
\hline Mixed paper & $18.7-24.6$ & $2.6-3.5$ & $290-317$ & $265-292$ \\
\hline Grass & $15.1-18.9$ & $2.5-3.3$ & $287-316$ & $266-299$ \\
\hline $\mathrm{RDF}$ & $17.4-27.1$ & $2.5-3.6$ & $288-323$ & $274-294$ \\
\hline
\end{tabular}

\section{ACKNOWLEDGEMENTS}

This project was funded by the Australian Research Council. S. H. acknowledges the Ministry of Science, Technology and Environment, Thailand, for sponsoring her postgraduate research scholarship at the University of Newcastle. The authors thank Drs Atul Bhargava and Ron Roberts of the University of Newcastle for their contribution to the experimental work.

\section{REFERENCES}

[1] Drysdale D.D. and Thomson H.E. (1990) "Ignition of PUFs: A comparison of modified and unmodified foams", Proc. Flame Retardants '90, Elsevier Applied Science, Barking, 191-205.

[2] Pinfold G. (1995) Solid Management Strategy: Sustainable Resource Management - The Permanent Waste Solution, Newcastle City Council, Australia.

[3] Atreya A., Carpentier C. and Harkleroad M. (1986) "Effect of sample orientation on piloted ignition and flame spread", Proc. $1^{\text {st }}$ Int. Symp. Fire Safety Scie., 97-109.

[4] Kashiwagi T., Ohlemiller T.J. and Werner K. (1987) "Effect of external radiant flux and ambient oxygen concentration on nonflaming gasification rates and evolved products of White Pine" Combustion and Flame 69, 331-345.

[5] Tran H.C. and White R.H. (1992) "Burning rate of solid wood measured in a heat release rate calorimeter" Fire and Materials 16, 197-206.

[6] Smith K.W. and King J.B. (1970) "Surface temperature of materials during radiant heating to ignition" Journal of Fire and Flammability 1, 272-288.

[7] Fangrat J., Hasemi Y., Yoshida M. and Hirata T. (1996) "Surface temperature at ignition of wooden base slabs" Fire Safety Journal 27, 249-259.

[8] Urbas J. and Parker W.J. (1993) "Surface temperature measurements on burning wood specimens in the cone calorimeter and the effect of grain orientation" Fire and Materials 17, 205-208.

[9] Koohyar A.N. and Sliepcevich C.M. (1967) Ignition of Wood by Flame Radiation, University of Oklahoma Research Institute Internal Memorandum, 1578-1; as cited by Smith and King (1970).

[10] Babrauskas V. (2003) Ignition Handbook, Fire Science Publishers, Issaquah.

[11] Scudamore M.J., Briggs P.J. and Prager F.H. (1991) "Cone calorimetry - A review of tests carried out on plastics for the association of plastic manufacturers in Europe" Fire and Materials 15, 6584. 
[12] Vanspeybroeck R., Van Hees P. and Vandervelde P. (1993) "Combustion behaviour of polyurethane flexible foams under cone calorimetry test conditions" Fire and Materials 17, 155166.

[13] Chan W.-C.R., Kelbon M. and Krieger B.B. (1985) "Modelling and experimental verification of physical and chemical processes during pyrolysis of a large biomass particle" Fuel 64, 1505-1513.

[14] Zhou Z., Torero J.L., Goudeau J.C. and Bregeon B. (1995) "On the propagation of a reaction front through a porous fuel in the presence of an opposed forced flow: Application to mixtures characteristic of municipal waste" Combustion Science and Technology 110-111, 123-146.

[15] Saastomoinen J.J., Taipale R., Horttanainen M. and Sarkomaa P. (2000) "Propagation of the ignition front in beds of wood particles" Combustion and Flame 123, 214-226.

[16] Bhargava A., Dlugogorski B.Z. and Kennedy E.M. (2001) "Fire properties of wood chips", Proc. Interflam 2001, Edinburgh, Scotland, UK, 1343-1348.

[17] Hirunpraditoon S., Dlugogorski B.Z. and Kennedy E.M. (2006) "Fire properties of surrogate refuse-derived fuels" Fire and Materials 30, 107-130.

[18] Hirunpraditkoon S., Dlugogorski B.Z. and Kennedy E.M. (2008) "Fire properties of refuse-derived fuels: Measurements of temperature profile and mass loss" Proc. $9^{\text {th }}$ Int. Symp. Fire Safety Scie., 765-776.

[19] Wilson M.T., Dlugogorski B.Z. and Kennedy E.M. (2002) "Uniformity of radiant heat fluxes in cone calorimeter", Proc. $7^{\text {th }}$ Int. Symp. Fire Safety Scie., 815-827.

[20] Delichatsios M.A. and Zhang J. (2012) "An alternative way for the ignition times for solids with radiation absorption in-depth by simple asymptotic solutions" Fire and Materials 36, 41-47.

[21] Jiang F., de Ris J.L. and Khan M.M. (2009) “Absorption of thermal energy in PMMA by in-depth radiation" Fire Safety Journal 44, 106-112.

[22] Linteris G.T. (2011) "Numerical simulations of polymer pyrolysis rate: Effect of property variations" Fire and Materials 35, 463-480.

[23] Abu-Zaid M.Z. (1988) Effect of Water on Ignition of Cellulosic Materials, PhD Thesis, Michigan State University, East Lansing, Michigan, USA.

[24] Atreya A. (1983) Pyrolysis, Ignition and Fire Spread on Horizontal Surfaces of Wood, PhD Thesis, Harvard University, Massachusetts, USA.

[25] Moghtaderi B. (1996) Combustion Characteristics of Solid Fuels under Fire Conditions, PhD Thesis, The University of Sydney, Australia.

[26] Rhodes T.R. and Quintiere J.G. (1996) "Burning rate and flame heat flux for PMMA in a cone calorimeter" Fire Safety Journal 26, 221-240.

[27] Hopkins D. Jr. and Quintiere J.G. (1996) "Material fire properties and predictions for thermoplastics" Fire Safety Journal 26, 241-268.

[28] Quintiere J. and Iqbal N. (1994) "An approximate integral model for the burning rate of a thermoplastic-like material" Fire and Materials 18, 89-98. 